\title{
Forekomst av epilepsi i de nordiske landene
}

BAKGRUNN Oppdatert kunnskap om forekomsten av epilepsi er nyttig for planlegging av helsetjenester til denne store og sammensatte pasientgruppen. Det er gjort omfattende epidemiologisk epilepsiforskning, men resultatene er vanskelige å sammenlikne på grunn av sprikende metodebruk. Formålet med denne artikkelen er å presentere kunnskapsbaserte estimater for forekomst av epilepsi i de nordiske land.

KUNNSKAPSGRUNNLAG Artikkelen er basert på et PubMed-søk med søkeordene epilepsy og epidemiology, kombinert med hvert av de nordiske landene for seg.

RESULTATER I 38 originalartikler ble det rapportert insidens og/eller prevalens av epilepsi $i$ et nordisk land. I fire studier hadde man unders $ø$ kt prevalensen av aktiv epilepsi i alle aldersgrupper, med resultater varierende fra 3,4 til 7,6 per 1000 innbyggere. I kun to studier hadde man unders $ø$ kt insidensen av epilepsi i et prospektivt materiale som inkluderte alle aldersgrupper. Rapportert insidens var henholdsvis 33 og 34 per 100000 personår. I en prospektiv studie som kun inkluderte voksne, var insidensen 56 per 100000 personår.

FORTOLKNING Vi anslår at rundt 0,6\% av Nordens befolkning har aktiv epilepsi, dvs. omtrent 30000 personer i Norge. Epilepsi er dermed en av de vanligste nevrologiske sykdommene. Insidensdata er mer usikre, men det er rimelig å anta at det dreier seg om 30-60 nye tilfeller per 100000 personår.

Epilepsi er en av de vanligste nevrologiske sykdommene, og den rammer mennesker i alle aldre (1). Epilepsidiagnosen innebærer ofte noe langt mer enn gjentatte uprovoserte epileptiske anfall. Diagnosen kan påvirke valg av yrke og utdanning, familie, sosialt samvær og mental helse $(2,3)$. Dette gjør at pasientgruppen har sammensatte behov for helse- og sosialtjenester. Oppdatert kunnskap om forekomsten av epilepsi er av betydning når slike tilbud skal planlegges.

I Norge er det anslått at 30000-40000 mennesker har diagnosen $(4,5)$, et estimat basert på epidemiologiske studier utført utenfor Norden. Geografiske og sosioøkonomiske forhold kan imidlertid påvirke forekomsten av epilepsi $(6,7)$. Epidemiologiske data må derfor ekstrapoleres med forsiktighet. De nordiske landene ligger ikke bare i geografisk nærhet til hverandre, de er også nokså ensartede hva gjelder kultur, levestandard og økonomi. Vi har derfor valgt å se på disse landene under ett. En god oversikt over nordiske epidemiologiske studier på epilepsi har manglet hittil. Hensikten med denne artikkelen er å angi det vi i dag mener er de beste estimatene for insidens og prevalens av epilepsi i de nordiske land.

\section{Kunnskapsgrunnlag}

Vi har foretatt en gjennomgang av originalartikler, basert på søk i Pubmed til og med 1.1. 2015. Vi søkte på ordene epilepsy og epidemiology ved hjelp av boolsk operator AND i kombinasjon med hvert enkelt av de nordiske landene for seg. Søket ga 141 treff for Norge, 262 for Sverige, 199 for Finland (inkludert Åland, som var uten treff), 213 for
Danmark (inkludert seks for Grønland og én for Færøyene) og 29 for Island.

Søkeresultatet ble gjennomgått ut fra tittel og sammendrag. Til sammen fant vi 38 engelsk-, norsk- eller danskspråklige originalartikler der prevalens og/eller insidens av epilepsi ble rapportert. Det var ingen finsk-, islandsk- eller svenskspråklige artikler.

Tilleggssøk med ordene epilepsy AND (incidence OR prevalence) for hvert av de nordiske landene ga 163 treff for Norge, 296 for Sverige, 247 for Finland (inkludert Åland), 243 for Danmark (inkludert seks for Grønland og én for Færøyene) og 30 for Island. Tilleggssøket identifiserte ingen flere relevante originalartikler. Søkeresultatet ble kryssjekket opp mot referanselister i sentrale engelskspråklige oversiktsartikler og kommentarer (6-9).

\section{Prevalens}

Prevalens defineres som andelen individer i en bestemt befolkning som har den aktuelle diagnosen på et gitt tidspunkt (prevalensdagen). Prevalens rapporteres vanligvis i prosent eller promille av den totale befolkningen i det aktuelle området.

Nordiske studier der man har undersøkt prevalens av epilepsi er vist $\mathrm{i}$ tabell 1 (10-38). I åtte av studiene er alle aldersgrupper inkludert $(10-13,26-29)$, men bare fire var begrenset til aktiv epilepsi (10-13). Fremgangsmåten for identifisering av pasienter var lik i de fire studiene av aktiv epilepsi, med sykehusbaserte søk og retrospektiv gjennomgang av sykejournaler. Dessverre var definisjonen av aktiv epilepsi forskjellig.

En av disse studiene ble gjennomført på

\author{
Marte Syvertsen \\ marsyv@vestreviken.no \\ Jeanette Koht \\ Nevrologisk avdeling \\ Drammen sykehus \\ Karl 0. Nakken
}

Spesialsykehuset for epilepsi

Oslo universitetssykehus

Jit

Engelsk oversettelse på www.tidsskriftet.no

HOVEDBUDSKAP

I epidemiologisk epilepsiforskning er det mange metodiske svakheter, noe som gjør at resultatene må tolkes med varsomhet

Det estimeres at omtrent 30000 nordmenn er under behandling for epilepsi og/eller har hatt minst ett epilepsianfall i løpet av de siste 2-5 år

Gode insidensstudier på epilepsi i Norden er mangelvare, men man antar at det er 30-60 nye tilfeller per 100000 innbyggere per år 
Tabell 1 Originalartikler om prevalens av epilepsi i de nordiske land. Studiene er sortert etter hvilke aldersgrupper som var inkludert og om studien var begrenset til pasienter med aktiv epilepsi

\begin{tabular}{|c|c|c|c|c|c|c|}
\hline $\begin{array}{l}\text { Førsteforfatter } \\
\text { (referanse) }\end{array}$ & $\AA ̊ ̊ r$ & Land & Alder (år) & $\begin{array}{c}\text { Preva- } \\
\text { lens per } \\
1000\end{array}$ & $\begin{array}{l}\text { Kun aktiv } \\
\text { epilepsi }\end{array}$ & $\begin{array}{l}\text { Antall } \\
\text { kasus }\end{array}$ \\
\hline Gudmundsson (10) & 1966 & Island & Alle & 3,4 & $\mathrm{Ja}$ & 635 \\
\hline Joensen (11) & 1986 & Færøyene & Alle & 7,6 & $\mathrm{Ja}$ & 333 \\
\hline Olafsson (12) & 1999 & Island & Alle & 4,8 & $\mathrm{Ja}$ & 428 \\
\hline Syvertsen (13) & 2015 & Norge & Alle & 6,5 & $\mathrm{Ja}$ & 1771 \\
\hline Breivik (14) & 2008 & Norge & $0-14$ & 3,8 & $\mathrm{Ja}$ & 114 \\
\hline Sillanpää (15) & 1973 & Finland & $0-15$ & 3,2 & $\mathrm{Ja}$ & 348 \\
\hline Eriksson (16) & 1997 & Finland & $0-15$ & 3,9 & $\mathrm{Ja}$ & 329 \\
\hline Sidenvall (17) & 1996 & Sverige & $0-16$ & 4,2 & Ja & 155 \\
\hline Larsson (18) & 2006 & Sverige & $0-16$ & 3,4 & Ja & 205 \\
\hline Brorson (19) & 1967 & Sverige & $0-19$ & 3,5 & $\mathrm{Ja}$ & 195 \\
\hline Becker-Christensen (20) & 1998 & Grønland & $0-19$ & 4,1 & $\mathrm{Ja}$ & 35 \\
\hline Waaler (21) & 2000 & Norge & $6-12$ & 5,1 & Ja & 198 \\
\hline Keränen (22) & 1989 & Finland & $>15$ & 6,3 & $\mathrm{Ja}$ & 1233 \\
\hline Forsgren (23) & 1992 & Sverige & $>17$ & 5,5 & $\mathrm{Ja}$ & 713 \\
\hline Svendsen (24) & 2007 & Norge & $31,41,46,61,76$ & 8,2 & Ja & 90 \\
\hline Brodtkorb (25) & 2008 & Norge & $18-65$ & 6,7 & $\mathrm{Ja}$ & 12 \\
\hline de Graaf (26) & 1974 & Norge & Alle & 3,5 & Nei & 749 \\
\hline Juul-Jensen (27) & 1975 & Danmark & Alle & 6,9 & Nei & 1675 \\
\hline Christensen (28) & 2007 & Danmark & Alle & 5,7 & $\mathrm{Nei}$ & $28303^{1}$ \\
\hline Bolin (29) & 2014 & Sverige & Alle & 8,8 & $\mathrm{Nei}$ & $81606^{1}$ \\
\hline Surén (30) & 2013 & Norge & $0-12$ & 6,6 & Nei & $5269^{1}$ \\
\hline Olesen (31) & 1996 & Grønland & $0-15$ & 5,9 & $\mathrm{Nei}$ & 15 \\
\hline Blichfeldt (32) & 2004 & Grønland & $0-15$ & 3,4 & $\mathrm{Nei}$ & 43 \\
\hline Li (33) & 2014 & Sverige & $2-17$ & 9,0 & $\mathrm{Nei}$ & 93091 \\
\hline Sillanpää (34) & 1992 & Finland & $4-15$ & 6,8 & $\mathrm{Nei}$ & 104 \\
\hline Baldin (35) & 2012 & Island & $7-15$ & 7,7 & $\mathrm{Nei}$ & 75 \\
\hline Wagner (36) & 1983 & Danmark & $16-66$ & 4,3 & $\mathrm{Nei}$ & 1054 \\
\hline Bakken (37) & 2014 & Norge & $18-82$ & 9,0 & $\mathrm{Nei}$ & $33571^{1}$ \\
\hline Löfgren (38) & 2009 & Finland & 39 & 19 & Nei & 222 \\
\hline
\end{tabular}

1 Registerbasert

Island for mer enn 50 år siden. Man fant her, ikke overraskende, et betydelig lavere prevalenstall $(3,4 / 1000)$ enn i de andre tre (10). Funnet er i tråd med en eldre studie fra Nord-Norge (prevalens 3,5/1 000) der alle aldersgrupper var inkludert, men som ikke var begrenset til aktiv epilepsi (26).
I de resterende tre studiene var prevalensen på henholdsvis 4,8/1 000 (12), 6,5/1 000 (13) og 7,6/1 000 (11). Studien med lavest prevalenstall var fra Island. I denne ble ubehandlede pasienter som hadde vært anfallsfrie i mer enn ett år ekskludert (12). Høyest prevalenstall ble funnet på Færøyene, til tross for ekskludering av alle pasienter som hadde vært anfallsfrie i mer enn fem år, uavhengig av behandling. Forfatteren begrunnet dette med at pasientjournalene ofte var skrevet av personell uten spesiell interesse for epilepsi, og at dette kan ha ført til en viss overdiagnostisering (11). Den siste studien er norsk. I den ble aktiv epilepsi definert som pågående behandling og/eller minst ett anfall de siste fem år (13). Så langt er dette den eneste studien der man har benyttet de nyeste retningslinjene for epidemiologisk epilepsiforskning fra International League Against Epilepsy (ILAE) og deres omfattende forslag til endring av terminologi fra $2010(39,40)$.

I åtte studier er forekomsten av aktiv epilepsi hos barn undersøkt (14-21). Prevalenstallene varierer fra 3,2 til 5,1 per 1000 innbyggere. Tatt $\mathrm{i}$ betraktning at forekomsten av epilepsi øker med økende alder (12), er det ikke overraskende at i studien med høyest prevalens var ikke de yngste barna (aldersgruppen 0-5 år) inkludert (21).

Prevalenstall for aktiv epilepsi hos voksne er rapportert i fire nordiske studier (22-25), hvorav to er fra Norge $(24,25)$. Vi mener det er grunn til å anta at begge disse har høy sensitivitet og spesifisitet når det gjelder identifisering av pasienter, da det ble benyttet populasjonsbaserte spørreskjemaer kombinert med henholdsvis individuelt intervju og sykehussøk/retrospektiv journalgjennomgang. Kohortene som ble undersøkt var imidlertid små. Prevalensen av aktiv epilepsi var henholdsvis 6,7 (24) og 8,2 per 1000 (25). De to øvrige nordiske studiene var basert på større populasjoner, og man fant en prevalens på henholdsvis 5,5 (23) og 6,3 per 1000 (22). I sistnevnte studie ble alle inkluderte pasienter undersøkt klinisk av forfatterne, slik at spesifisiteten antas å ha vært høy.

\section{Insidens}

Insidens defineres som andelen individer som i en bestemt populasjon får diagnosen $\mathrm{i}$ en gitt tidsperiode. Insidensen rapporteres vanligvis som antall nye tilfeller per 100000 personer per år. Nordiske studier der man har undersøkt insidens av epilepsi er vist i tabell $2(10,11,14,15,18,22,26-28$, 41-49). Fordi slike studier ofte er vanskeligere å gjennomføre i praksis, er det færre insidens- enn prevalensstudier. For å sikre høyest mulig sensitivitet og spesifisitet bør insidensstudier være prospektive (9). Det bør dessuten noteres om studien også inkluderer enkeltstående uprovoserte anfall eller om den er begrenset til ILAEs definisjon av epilepsi $(40,50)$. Dette er spesielt relevant for prospektive insidensstudier, siden flere av dem registrerer alle som kommer inn med førstegangs epileptisk anfall og rapporterer 
dette tallet, uten å vente på om pasientene får et anfall nummer to. Definisjonene på epilepsi som er brukt i studiene vi refererer til i denne oversiktsartikkelen, er oppsummert i tabell $3(10-38,41-49)$.

I Norden er det gjennomført kun fem prospektive insidensstudier av epilepsi (41-45), hvorav bare to omfattet alle aldersgrupper. I studien med størst populasjonsgrunnlag, der enkeltstående uprovoserte anfall var inkludert (42), ble det funnet en årlig insidens på 34/100 000. I en prospektiv studie fra Island fant man en insidens på 33/ 100000 . Her var enkeltstående uprovoserte anfall ekskludert (41).

I en mindre prospektiv undersøkelse blant barn fant man en årlig insidens av epilepsi på 53/100 000 (44). I en prospektiv undersøkelse med voksne pasienter fant man en insidens på 56/100 000. Her var enkeltstående uprovoserte anfall inkludert (45).

\section{Diskusjon}

I 2011 publiserte ILAE nye retningslinjer for epidemiologisk forskning på epilepsi (39) dette fordi sprikende metodebruk gjorde sammenlikning av studier vanskelig $(6,7)$. I epidemiologiske studier defineres vanligvis epilepsi som minimum to uprovoserte epileptiske anfall med mer enn 24 timers mellomrom $(39,51)$. Dette var også ILAEs definisjon inntil 2014, da den ble utvidet til også å omfatte ett uprovosert anfall dersom det er ledd $i$ et epilepsisyndrom eller dersom risikoen for nye anfall vurderes til å være over $60 \%(50)$.

Studier der enkeltstående uprovoserte og/ eller akutte symptomatiske anfall er inkludert, vil naturligvis gi en høyere epilepsiforekomst enn studier der man har ansett at slike anfall ikke kvalifiserer for diagnosen.

Ifølge ILAE-definisjonen er aktiv epilepsi en tilstand med pågående behandling med antiepileptisk medikasjon og/eller minst ett epileptisk anfall i løpet av en definert tidsperiode, vanligvis de siste 2-5 år. Det anbefales at man i epidemiologiske studier holder seg til rapportering av aktiv epilepsi $(39,51)$. Her er det imidlertid fremdeles rom for diskrepans - jo kortere tidsperiode fra siste anfall, desto flere vil bli ekskludert fra gruppen med aktiv epilepsi. For dem som har vært anfallsfrie i mer enn ti år og har vært uten antiepileptisk medikasjon i mer enn fem år, har ILAE introdusert begrepet «resolved epilepsy» (50). Det betyr at epilepsien er i tilbakegang, ikke at sykdommen er kurert. Begrepet er foreløpig ikke tatt i bruk i epidemiologiske studier.

En annen årsak til sprikende funn er variasjon i metode for identifisering av pasienter. Ingen metode er helt vanntett. Derfor blir det problematisk å anbefale én fremgangsmåte alene. Studier der man har benyttet et popu-

Tabell 2 Originalartikler om insidens av epilepsi i de nordiske land. Artiklene er sortert etter studiedesign og alder på inkluderte pasienter

\begin{tabular}{|c|c|c|c|c|c|}
\hline $\begin{array}{l}\text { Førsteforfatter } \\
\text { (referanse) }\end{array}$ & $\AA ̊ \AA r$ & Land & Alder (år) & $\begin{array}{l}\text { Insidens per } \\
100000 \text { personår }\end{array}$ & Design \\
\hline Olafsson (41) & 2005 & Island & Alle & 33 & Prospektiv \\
\hline Adelöw (42) & 2009 & Sverige & Alle & 34 & Prospektiv ${ }^{1}$ \\
\hline Sidenvall (43) & 1993 & Sverige & $0-15$ & 73 & Prospektiv ${ }^{1}$ \\
\hline Braathen (44) & 1995 & Sverige & $0-16$ & 53 & Prospektiv \\
\hline Forsgren (45) & 1996 & Sverige & $>17$ & 56 & Prospektiv ${ }^{1}$ \\
\hline Gudmundsson (10) & 1966 & Island & Alle & 26 & Retrospektiv \\
\hline de Graaf (26) & 1974 & Norge & Alle & 33 & Retrospektiv \\
\hline Juul-Jensen (27) & 1975 & Danmark & Alle & 30 & Retrospektiv ${ }^{1}$ \\
\hline Joensen (11) & 1986 & Færøyene & Alle & 43 & Retrospektiv \\
\hline Olafsson (46) & 1996 & Island & Alle & 47 & Retrospektiv \\
\hline Sillanpää (47) & 2006 & Finland & Alle & 53 & Retrospektiv \\
\hline Christensen (28) & 2007 & Danmark & Alle & 69 & Retrospektiv \\
\hline Breivik (14) & 2008 & Norge & $0-14$ & 47 & Retrospektiv \\
\hline Sillanpää (15) & 1973 & Finland & $0-15$ & 25 & Retrospektiv \\
\hline Blom (48) & 1978 & Sverige & $0-15$ & 82 & Retrospektiv \\
\hline Larsson (18) & 2006 & Sverige & $0-16$ & 40 & Retrospektiv \\
\hline Brorson (49) & 1987 & Sverige & $0-19$ & 50 & Retrospektiv \\
\hline Keränen (22) & 1989 & Finland & $>15$ & 24 & Retrospektiv \\
\hline
\end{tabular}

1 Enkeltstående uprovoserte anfall inkludert

lasjonsbasert spørreskjema, kan ha begrensninger på grunn av lav svarprosent og seleksjonsskjevhet. Dessuten kan slike studier av praktiske årsaker være begrenset til mindre populasjoner eller avgrensede aldersgrupper, i likhet med dør-til-dør-undersøkelser.

Studier basert på registrerte diagnosekoder kan gi store studiepopulasjoner, men man risikerer å overestimere sykdomsforekomsten. Slike studier kan dessuten vanskelig begrenses til aktiv epilepsi. En undersøkelse fra Danmark viste at rundt $20 \%$ av pasientene som var registrert med epilepsikode, ikke oppfylte ILAEs epilepsidefinisjon (52). I vår nylige studie fra Buskerud gjorde vi tilsvarende funn (13). Retrospektiv journalgjennomgang for validering av diagnosen vil naturligvis øke spesifisiteten, men da er man avhengig av at journalopplysningene er korrekte og at registreringen er foretatt av kompetent personell.

Variasjon i alder på populasjonen som er studert, er et annet problem. I kun et fåtall studier fra Norden er alle aldersgrupper inkludert. Studier som er begrenset til en spesifikk aldersgruppe kan vanskelig ekstra- poleres til hele befolkningen, da det tidligere er vist at forekomsten av epilepsi er økt i den eldste del av befolkningen (12). Dette er en trend som også gjør seg gjeldende i materialet vi har samlet her. I studier der man har undersøkt forekomst av aktiv epilepsi hos barn og ungdom (0-19 år), varierer prevalensen fra 3,2 til 4,1 per 1000 (14-20), mens prevalensen av aktiv epilepsi hos voksne ligger høyere $(5,5-8,2 / 1000)$ (22-25). I Norden er det ikke gjort isolerte undersøkelser av forekomsten hos eldre, heller ikke er dette undersøkt i ungdomsgruppen.

Når det gjelder insidens, er studiene $\mathrm{i}$ dette materialet for få og resultatene for sprikende til at det kan trekkes konklusjoner angående aldersfordeling. Det er imidlertid kjent at insidenskurven for epilepsi har en topuklet utforming, med en topp tidlig i livet og en ny økning i de eldste aldersgruppene (53).

Beklageligvis er epilepsi fremdeles en stigmatiserende diagnose (54). At enkelte ønsker å holde diagnosen skjult, kan føre til underrapportering i visse samfunn eller 
Tabell 3 Definisjoner på epilepsi og aktiv epilepsi brukt i de inkluderte originalstudiene av prevalens og/eller insidens

\section{Definisjon på epilepsi}

$>1$ uprovosert epileptisk anfall

\section{Referanse}

$>2$ uprovoserte epileptiske anfall

$>2$ uprovoserte epileptiske anfall med > 24 t mellomrom

> 3 uprovoserte epileptiske anfall med > 1 ukes mellomrom

Kronisk hjerneorganisk lidelse med gjentatte epileptiske anfall

Gjentatte epileptiske anfall de siste tre år

$27,42,43,45$

$19,36,49$

$11,13,14,17,18,21-23$

$25,41,46$

15

26,34

Gjentatte uprovoserte epileptiske anfall

48

$12,16,24$

Gjentatte uprovoserte anfall av cerebral opprinnelse

44

Paroksysmal og transitorisk forstyrrelse av hjernefunksjonen som $\quad 10$

utvikles plutselig, stopper spontant og har tendens til gjentakelse

> 2 uprovoserte epileptiske anfall/1 anfall og funn av epileptisk

aktivitet i EEG/godkjent refusjon av utgifter til antiepileptika

Registrert med ICD-10-kode for epilepsi

Godkjent refusjon av utgifter til antiepileptika

$28-30,33,37$

Bekreftende svar på spørsmål om epilepsi i spørreskjema

Ikke angitt

$20,31,32$

\section{Definisjon på aktiv epilepsi}

> 1 anfall det siste året og/eller antiepileptisk medikasjon

\section{Referanse}

> 1 anfall de siste 2 år og/eller antiepileptisk medikasjon 12

> 1 anfall de siste 3 år, uavhengig av medikasjon

> 1 anfall de siste 4 år, uavhengig av medikasjon

> 1 anfall de siste 5 år, uavhengig av medikasjon

15,21

> 1 anfall de siste 5 år og/eller antiepileptisk medikasjon

$11,14,18,25$

$10,13,16,17,22-24$

aldersgrupper. Kanskje er denne feilkilden større i eldre studier, kanskje gjelder det også studier fra utkantstrøk.

\section{Konklusjon}

Epidemiologisk forskning på epilepsi er ingen eksakt vitenskap. Alle metodene som benyttes har feilkilder. En god beskrivelse av metoden og dens begrensninger samt en felles epilepsidefinisjon er viktig i all slik forskning. Studier basert på oppdaterte retningslinjer og epilepsiklassifisering er fremdeles mangelvare - ikke bare i Norden, men også på verdensbasis.

Basert på denne litteraturgjennomgangen er det rimelig å anta at den reelle forekomsten av aktiv epilepsi i Norden ligger på rundt 6 per 1000 , dvs. at rundt 30000 mennesker

i Norge har aktiv epilepsi. Insidensdataene er mer usikre. Med utgangspunkt i de få prospektive studiene som er gjort, anslås årlig insidens til 30-60 nye tilfeller per 100000 innbyggere.

\section{Marte Syvertsen (f. 1982)}

er lege i spesialisering. Hun jobber med et forskningsprosjekt basert på epidemiologiske data om epilepsi i Buskerud fylke.

Forfatter har fylt ut ICMJE-skjemaet og oppgir ingen interessekonflikter.

\section{Jeanette Koht (f. 1969)}

er forsker, spesialist i nevrologi og overlege. Forfatter har fylt ut ICMJE-skjemaet og oppgir ingen interessekonflikter.

\section{Karl O. Nakken (f. 1945)}

er spesialist i nevrologi, med spesialkompetanse på epilepsisykdommene, og medisinsk sjef.

Forfatter har fylt ut ICMJE-skjemaet og oppgir ingen interessekonflikter.

\section{Litteratur}

1. Hirtz D, Thurman DJ, Gwinn-Hardy K et al. How common are the «common» neurologic disorders? Neurology 2007; 68: 326-37.

2. Nakken KO, Brodtkorb E, Koht J. Epilepsi og rehabilitering. Tidsskr Nor Lægeforen 2007; 127: 309-12.

3. Alfstad KA, Clench-Aas J, Van Roy B et al. Psychiatric symptoms in Norwegian children with epilepsy aged $8-13$ years: effects of age and gender? Epilepsia 2011; 52: 1231-8.

4. Gjerstad L, Taubøll E. Hva er epilepsi? Tidsskr Nor Lægeforen 2003; 123: 1359-61.

5. Nakken KO. Epilepsi. 2 utg. Oslo: Cappelen Akademisk, 2010: 29

6. Bell GS, Neligan A, Sander JW. An unknown quantity-the worldwide prevalence of epilepsy. Epilepsia 2014; 55: 958-62.

7. Beghi E, Hesdorffer D. Prevalence of epilepsy-an unknown quantity. Epilepsia 2014; 55: 963-7.

8. Banerjee PN, Filippi D, Allen Hauser W. The descriptive epidemiology of epilepsy-a review. Epilepsy Res 2009; 85: 31-45.

9. Forsgren L, Beghi E, Oun A et al. The epidemiology of epilepsy in Europe - a systematic review. Eur J Neurol 2005; 12: 245-53.

10. Gudmundsson G. Epilepsy in Iceland. A clinical and epidemiological investigation. Acta Neurol Scand 1966; 43 (suppl 25): 1-124

11. Joensen P. Prevalence, incidence, and classification of epilepsy in the Faroes. Acta Neurol Scand 1986; 74: $150-5$.

12. Olafsson E, Hauser WA. Prevalence of epilepsy in rural Iceland: a population-based study. Epilepsia 1999; 40: 1529-34

13. Syvertsen M, Nakken KO, Edland A et al. Prevalence and etiology of epilepsy in a Norwegian county-A population based study. Epilepsia 2015 56: 699-706.

14. Breivik N, Reiher T. Epilepsi hos barn på Sunnmøre. Tidsskr Nor Legeforen 2008; 128: 2049-51.

15. Sillanpää M. Medico-social prognosis of children with epilepsy. Epidemiological study and analysis of 245 patients. Acta Paediatr Scand Suppl 1973; 237: $3-104$

16. Eriksson KJ, Koivikko MJ. Prevalence, classification, and severity of epilepsy and epileptic syndromes in children. Epilepsia 1997; 38: 1275-82.

17. Sidenvall R, Forsgren L, Heijbel J. Prevalence and characteristics of epilepsy in children in northern Sweden. Seizure 1996; 5: 139-46.

18. Larsson K, Eeg-Olofsson O. A population based study of epilepsy in children from a Swedish county. Eur J Paediatr Neurol 2006; 10: 107-13.

19. Brorson LO. A survey of epilepsy among children and young people in the county of Uppsala. Acta Neurol Scand 1967; 43 (suppl 31): 163

20. Becker-Christensen FG. Sygdomme og helbredsproblemer hos børn i Grønland. En epidemiologisk undersøgelse baseret på henvisninger til paediatrisk speciallægeundersøgelse i otte grønlandske distrikter 1992-94. Ugeskr Læger 1998; 160 : 2856-62

21. Waaler PE, Blom BH, Skeidsvoll H et al. Prevalence, classification, and severity of epilepsy in children in western Norway. Epilepsia 2000; 41 : 802-10.

22. Keränen T, Riekkinen PJ, Sillanpää M. Incidence and prevalence of epilepsy in adults in eastern Finland. Epilepsia 1989; 30: 413-21. 
23. Forsgren L. Prevalence of epilepsy in adults in northern Sweden. Epilepsia 1992; 33: 450-8.

24. Svendsen T, Lossius M, Nakken KO. Age-specific prevalence of epilepsy in Oppland County, Norway. Acta Neurol Scand 2007; 116: 307-11.

25. Brodtkorb E, Sjaastad O. Epilepsy prevalence by individual interview in a Norwegian community. Seizure 2008; 17: 646-50.

26. de Graaf AS. Epidemiological aspects of epilepsy in northern Norway. Epilepsia 1974; 15: 291-9.

27. Juul-Jensen P. Ipsen J. Prævalens og inciden af epilepsi i Stor-Århus. Ugeskr Læger 1975; 137. 2380-8.

28. Christensen J, Vestergaard M, Pedersen MG et al. Incidence and prevalence of epilepsy in Denmark. Epilepsy Res 2007; 76: 60-5.

29. Bolin K, Berggren F, Landtblom AM. Prevalence and cost of epilepsy in Sweden-a register-based approach. Acta Neurol Scand 2015; 131: 37-44.

30. Surén P. Bakken IJ, Lie KK et al. Fylkesvise forskjeller i registrert forekomst av autisme, AD/HD, epilepsi og cerebarl parese i Norge. Tidsskr Nor Legeforen 2013; 133: 1929-34

31. Olesen T. Paediatrisk sygdoms- og symptomprofil i Sydgrønland. Erfaringer fra konsulentbes $\varnothing g$ i 1992. Ugeskr Læger 1996; 158: 52-4.

32. Blichfeldt S, Bille T, Nielsen IM et al. Epilepsy among children in Greenland. Int J Circumpolar Health 2004; 63 (suppl 2): 363-5

33. Li X, Sundquist J, Zöller B et al. Neighborhood, family, and childhood and adolescent epilepsy: a nationwide epidemiological study from Sweden. Seizure 2014; 23: 62-8.

34. Sillanpää M. Epilepsy in children: prevalence, disability, and handicap. Epilepsia 1992; 33: 444-9

35. Baldin E, Ludvigsson P. Mixa O et al. Prevalence of recurrent symptoms and their association with epilepsy and febrile seizure in school-aged child- ren: a community-based survey in Iceland. Epilepsy Behav 2012: 23: 315-9.

36. Wagner AL. A clinical and epidemiological study of adult patients with epilepsy. Acta Neurol Scand Suppl 1983; 94: 63-72

37. Bakken IJ, Revdal E, Nesvåg R et al. Substance use disorders and psychotic disorders in epilepsy: a population-based registry study. Epilepsy Res 2014; 108: 1435-43

38. Löfgren E, Pouta A, von Wendt L et al. Epilepsy in the northern Finland birth cohort 1966 with special reference to fertility. Epilepsy Behav 2009: 14: 102-7.

39. Thurman DJ, Beghi E, Begley CE et al. Standards for epidemiologic studies and surveillance of epilepsy. Epilepsia 2011; 52 (suppl 7): 2-26.

40. Berg AT, Berkovic SF, Brodie MJ et al. Revised terminology and concepts for organization of seizures and epilepsies: report of the ILAE Commission on Classification and Terminology, 2005-2009. Epilepsia 2010; 51: 676-85.

41. Olafsson E, Ludvigsson P. Gudmundsson $\mathrm{G}$ et al. Incidence of unprovoked seizures and epilepsy in Iceland and assessment of the epilepsy syndrome classification: a prospective study. Lancet Neurol 2005; 4: 627-34

42. Adelöw C, Andell E, Amark P et al. Newly diagnosed single unprovoked seizures and epilepsy in Stockholm, Sweden: First report from the Stockholm Incidence Registry of Epilepsy (SIRE). Epilepsia 2009; 50: 1094-101.

43. Sidenvall R, Forsgren L, Blomquist HK et al. A community-based prospective incidence study of epileptic seizures in children. Acta Paediatr 1993; 82: 60-5

44. Braathen G. Theorell K. A general hospital population of childhood epilepsy. Acta Paediatr 1995; 84 : 1143-6.

45. Forsgren L, Bucht G, Eriksson S et al. Incidence and clinical characterization of unprovoked seizures in adults: a prospective population-based study. Epilepsia 1996; 37: 224-9.

46. Olafsson E, Hauser WA, Ludvigsson P et al. Incidence of epilepsy in rural Iceland: a populationbased study. Epilepsia 1996; 37: 951-5.

47. Sillanpää M, Kälviäinen R, Klaukka T et al. Temporal changes in the incidence of epilepsy in Finland nationwide study. Epilepsy Res 2006; 71: 206-15.

48. Blom S, Heijbel J, Bergfors PG. Incidence of epilepsy in children: a follow-up study three years after the first seizure. Epilepsia 1978; 19: 343-50.

49. Brorson LO, Wranne L. Long-term prognosis in childhood epilepsy: survival and seizure prognosis Epilepsia 1987; 28: 324-30.

50. Fisher RS, Acevedo C, Arzimanoglou A et al. ILAE official report: a practical clinical definition of epilepsy. Epilepsia 2014; 55: 475-82.

51. Commission on Epidemiology and Prognosis, International League Against Epilepsy. Guidelines for epidemiologic studies on epilepsy. Epilepsia 1993: 34: 592-6.

52. Christensen J, Vestergaard M, Olsen J et al. Validation of epilepsy diagnoses in the Danish National Hospital Register. Epilepsy Res 2007; 75: $162-70$

53. Kotsopoulos IA, van Merode T, Kessels FG et al. Systematic review and meta-analysis of incidence studies of epilepsy and unprovoked seizures. Epilepsia 2002; 43: 1402-9.

54. Tuft M, Nakken KO. Epilepsi som stigma - ond, hellig eller gal? Tidsskr Nor Legeforen 2014; 134 2328-30.

Mottatt 14.4. 2015, første revisjon innsendt 29.6. 2015, godkjent 14.8. 2015. Redaktør: Trine B. Haugen. 